\title{
Análisis multitemporal mediante teledetección espacial y SIG del cambio de cobertura del suelo en el municipio de Danlí, El Paraíso, en los años $1987-2011$
}

\author{
Alicia Maricela Cárcamo y \\ Juan Gregorio Rejas Ayuga
}

\section{Resumen}

El municipio de Danlí se encuentra situado en la zona oriental de Honduras. Tiene una extensión aproximada de $2500 \mathrm{~km} 2$, cuenta con 37 aldeas y una población proyectada de 181,500 habitantes. Está constituido por zona urbana, zonas productoras de tabaco, granos básicos, ganado vacuno y cuenta además con áreas de vegetación principalmente bosques de conífera y bosque mixto. A pesar de ser una de las ciudades más importantes de la región no cuenta con planes de desarrollo bien establecidos por lo que se ha experimentado un crecimiento urbano desordenado y establecimiento de zonas agropecuarias sin el control adecuado que asegure el desarrollo sostenible.

La teledetección espacial permite la disponibilidad de imágenes satelitales, las cuales pueden ser analizadas usando Sistemas de Información Geográfica para establecer de manera automatizada los cambios ocurridos en el territorio en un amplio período de tiempo. En el presente artículo se expone el análisis multitemporal de imágenes LandSat y la evaluación de los cambios de cobertura del terreno ocurridos en un período de 11 años, entre 1987 y 2011. Para ello se ha desarrollado clasificación digital de imagen que ha sido supervisada en el área de estudio. Se presentan la cartografía temática generada y los resultados obtenidos, indicativos de la dinámica de usos de suelo en la región. Finalmente se analiza la metodología aplicada en lo referente a su impacto como importante herramienta de diagnóstico, así como en las tendencias que serán de utilidad para una mejor toma de decisiones en pro del desarrollo y bienestar de la zona y sus habitantes.

Palabras clave: SIG. Clasificación digital. Análisis multitemporal. Detección de cambios. Desarrollo. 


\section{Abstract}

Danli town is located in the eastern of Honduras. It has an area of approximately $2500 \mathrm{~km} 2$, has 37 villages and a projected population of 181.500 inhabitants. It consists of urban, snuff producing areas, basic grains, cattle and also has vegetation areas mainly conifer forests and mixed forest. Despite being one of the most important cities of the region has well established development plans so it has experienced urban sprawl and agricultural zoning without careful management to ensure sustainable development.

The remote sensing allows the availability of satellite images, which can be analyzed using GIS to establish an automated changes in the territory in an extended period of time. This article outlines the multitemporal analysis of Landsat and evaluation of land cover changes occurred in a 11-year period between 1987 and 2011. This classification was developed digital image that has been monitored in the study area. Thematic mapping presents the results generated and indicative of the dynamic soil uses in the region. Finally we analyze the methodology applied in relation to its impact as an important diagnostic tool, and trends that will be useful for better decision-making for development and welfare of the area and its inhabitants.

Keywords: GIS. Digital Classification. Multitemporal Analysis. Change Detection. Development.

Alicia Maricela Cárcamo (aliciacarcamou@gmail.com), Universidad Autónoma Nacional de Honduras, UNAH. Juan Gregorio Rejas Ayuga (juangregorio.rejas@upm.es), Universidad Politécnica de Madrid, UPM. 


\section{INTRODUCCIÓN}

La aplicación de técnicas de teledetección para la identificación y el estudio de los cambios de estas coberturas de suelo ha supuesto un importante avance en cuanto al detalle y cantidad de información obtenidos. Se muestran en este trabajo el material disponible en la actualidad para realizar este tipo de estudios en la región y se discute el potencial de cada uno dependiendo de la zona, los recursos disponibles y el detalle buscado.

La teledetección espacial permite la disponibilidad de imágenes satelitales, las cuales pueden ser analizadas usando Sistemas de Información Geográfica (SIG) para establecer de manera automatizada los cambios ocurridos en el territorio en un amplio período de tiempo. La aplicación de técnicas de teledetección en conjunción con SIG para la identificación, estudio y análisis de los cambios de estas coberturas de suelo ha supuesto un importante avance en cuanto al detalle y extracción de clases espectrales e informacionales en un determinado área de estudio. Se presenta en este trabajo la cartografía temática generada y los resultados obtenidos, indicativos de la dinámica de usos de suelo en la región de Danlí y su entorno. Finalmente se analiza la metodología aplicada en lo referente a su impacto como importante herramienta de diagnóstico, así como en las tendencias que serán de utilidad para una mejor toma de decisiones en pro del desarrollo y bienestar de la zona y sus habitantes.

\section{2. ÁREA DE ESTUDIO. MUNICIPIO DE DANLIY YENTORNO}

El municipio de Danlí, en el departamento de El Paraíso, tiene una extensión de aproximadamente $2,500 \mathrm{~km} 2$, se encuentra ubicado en la zona oriental de Honduras, fronterizo con Nicaragua. Se compone de 37 aldeas, 652 caseríos con una población proyectada al 2010 de 181,587 habitantes (Secretaría de Gobernación).

El territorio es irrigado por los ríos San Francisco, Vallecillo, Siale, Guayambre y la quebrada El Magullar, entre otros de menor caudal. Dentro de los límites del municipio se encuentra una gran porción del Valle de Camastrón que es una zona dedicada a las labores agropecuarias, asimismo podemos encontrar bosques de Coníferas denso, coníferas ralo, latifoliado y bosque mixto (según clasificación de usos del suelo de 1995) y las zonas urbanas que incluye aldeas, caseríos y la zona urbana principal que lleva el mismo nombre del municipio. En la Figura 1 se muestran la localización de la zona de estudio. 
La economía del municipio de Danlí está en la maquila del tabaco y sus productos agropecuarios. El tabaco suministra alrededor de 30.000 empleos directos en la fabricación de puros tipo cubano de exportación, el mayor comprador es los Estados Unidos con 80\% de sus productos el resto Europa. En agricultura es unos de los mayores productores de maíz, sorgo y frijol del país junto al café, en menor escala tomate, chile picante y dulce, sandías, maracuyá. Se tiene un buen pie de cría en ganado, cerdos y pollos. En cuanto a la producción artesanal, se generan en la zona tallas en madera, fabricas de rosquillas, de queso y quesillo, dulces, vinos de frutas y la famosa mistela.

Figura 1: Zona de estudio. Municipio de Danlí, El Paraíso (Honduras)

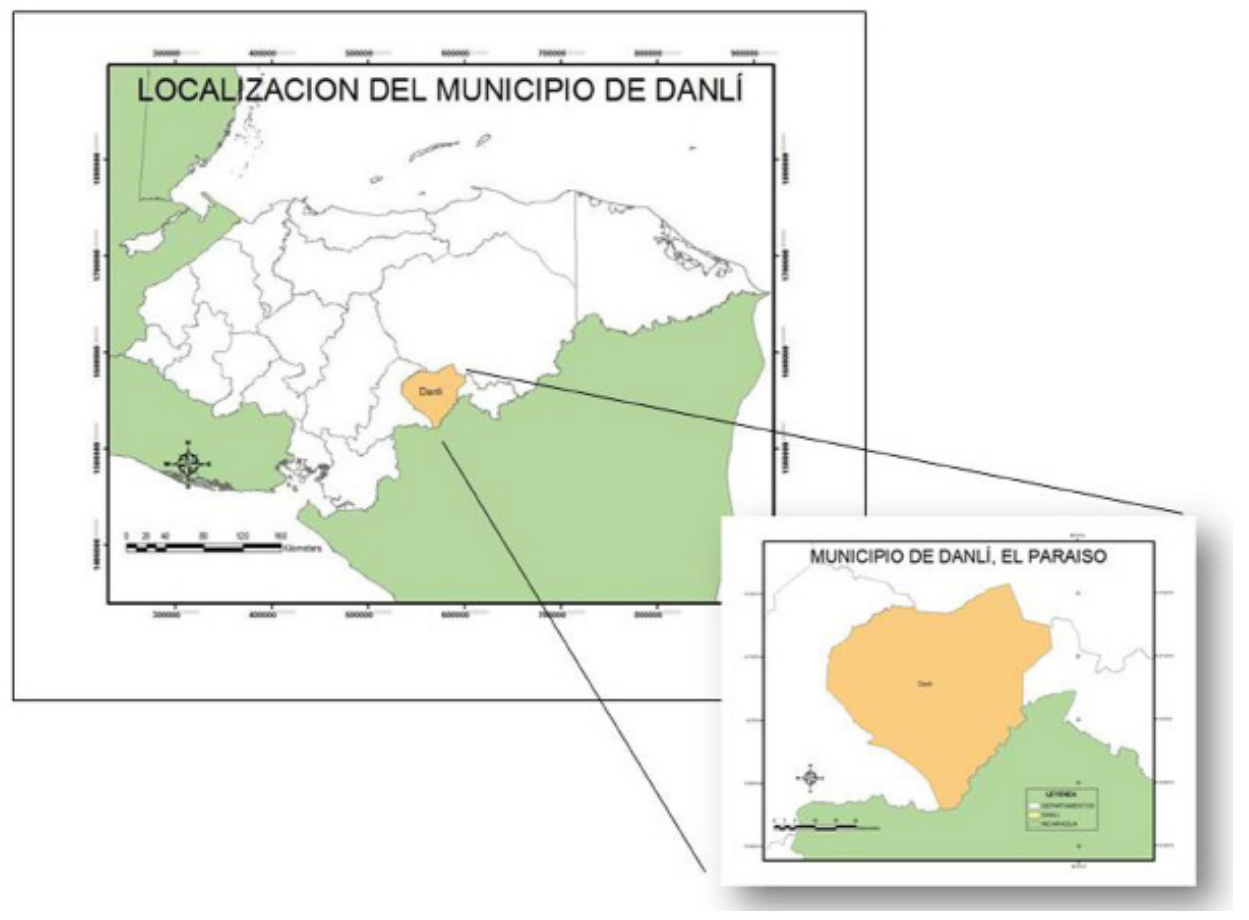

\section{MATERIAL Y MÉTODOS}

El desarrollo de los SIG y la teledetección han abierto un amplio abanico de posibilidades de análisis territoriales, siendo en la actualidad una herramienta sumamente importante y útil para conocer la dinámica de cambio de coberturas y hacer proyecciones acertadas basadas en procesos analíticos. La teledetección permite, mediante sensores instalados en plataformas espaciales, la obtención de 
imágenes de la superficie terrestre. Las imágenes captadas por estos sensores, imágenes satelitales, proveen una visión amplia de la superficie terrestre permitiendo una mejor comprensión de la organización espacial y brindan información que pasa desapercibida ante nuestros ojos como las bandas infrarrojas.

En este estudio se utilizó una serie de imágenes TM de LandSat 5 de los años 1987. 1997 y 2011, analizadas con el software Erdas Imagine. Se utilizaron coberturas existentes en el país, de límites administrativo para delimitar el área de estudio, áreas protegidas, capacidad de uso y clasificación Simmons del suelo, vías de comunicación, hojas cartográficas digitales así como de cobertura del suelo, que son generales para todo el país. Se realizó verificación de campo para la validación de los resultados obtenidos del análisis haciendo un recuento fotográfico y georreferenciación.

\subsection{Datos Espaciales}

El trabajo que se presenta supone un estudio inédito hasta la fecha en la zona, sobre los cambios de usos de suelo y su dinámica temporal en el período comprendido entre 1987 y 2011, utilizando una serie de imágenes TM de LandSat 5 y ETM+ de LandSat 7 USGS adquiridas a través de la plataforma Earth Explorer del Servicio Geológico de Estados Unidos - United States Geological Survey USGS (http://earthexplorer.usgs.gov/). Las imágenes han sido pre procesadas, transformando a valores de reflectancia y aplicando fusión de imagen a los canales multiespectrales del sensor con el canal pancromático en el caso del sensor ETM+.

Asimismo, el conjunto de datos espaciales ha sido georreferenciado en Sistema de Referencia WGS84 (World Geodetic System 1984) y proyección cartográfica UTM zona 16. 
Figura 2: TM 1987 (izqda.) y 2011 (dcha.) rgb 5, 4, 1. Detalle de la ciudad de Danlí y entorno
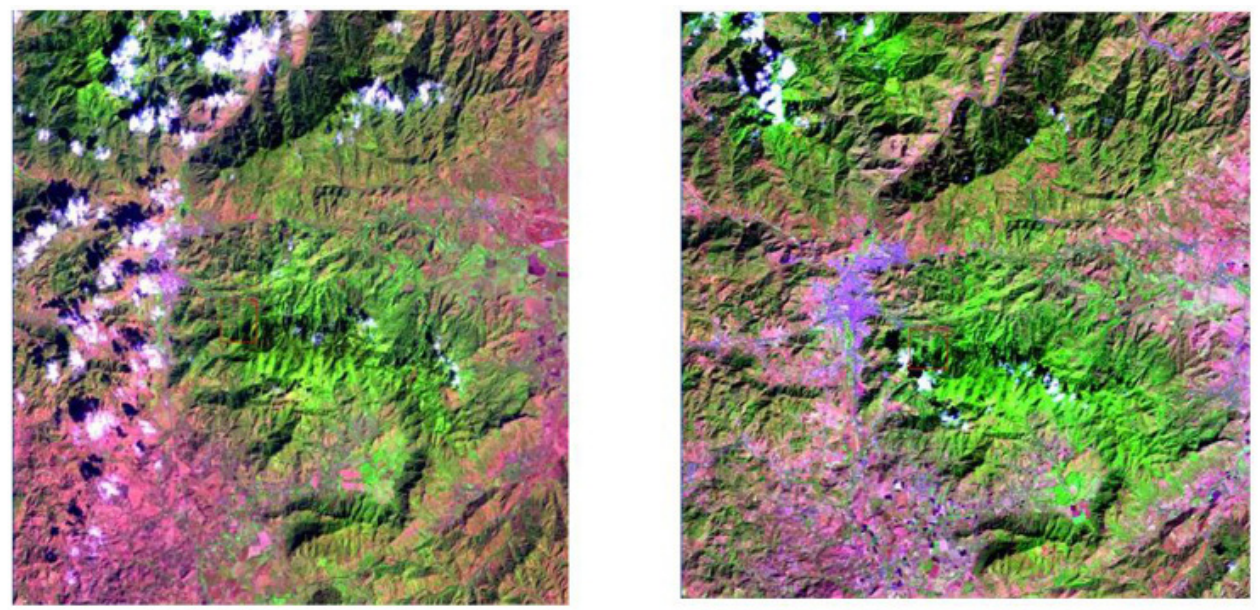

\subsection{Clasificación digital de imagen}

Se ha seguido una técnica sucesiva de clasificación digital mediante un método no supervisado, extrayendo siete tipos de cubiertas principales en el área de estudio. El estudio de las coberturas vegetales se ha abordado desde una perspectiva global, intentando adoptar un sistema de clasificación adoptado internacionalmente que uniforme los estudios de coberturas que se realizarán en diferentes áreas de la región centroamericana. Se ha aplicado una variante del sistema LCCS (Land Cover Classification System) propuesto por la FAO (Di Gregorio y Jansen, 2000) y adaptado a las características y coberturas del terreno propias, y que ha sido ya utilizado con anterioridad en Centroamérica para estudios a nivel regional (Latifovic et al., 2004).

Las superficies objeto de estudio son las cubiertas presentes en las áreas urbanas y no urbanas de Danlí y su entorno. Los principales tipos de cubierta presentes en la zona responden a vegetación, suelos, cultivos y materiales artificiales habitualmente empleados en edificios destinados a vivienda y en edificios industriales, y asfalto en muy pequeño porcentaje respecto al global de la escena. Dentro de estos resultan de especial interés los que puedan producir una contaminación por contacto, como pueda ser el amianto, y los que por su propia naturaleza induzcan procesos dinámicos, como son los cultivos y las grandes áreas forestales (Arango et al., 2005).

La primera tarea, por lo tanto ha sido definir una leyenda (ver Tabla) con las 
superficies de interés susceptibles de producir una respuesta registrada en el píxel de $15 \mathrm{~m}$ y $30 \mathrm{~m}$ de resolución espacial de la imagen, que abarcara la variabilidad de materiales y que supusieran a priori un valor añadido a la hora de confeccionar una actualización de la cartografía temática en un espacio, salvo las ciudades de Danlí y El Paraíso, eminentemente natural y rural.

El planteamiento metodológico propuesto está enfocado a la extracción de la información a partir de la propia imagen, minimizando el trabajo de campo y la información procedente de librerías espectrales.

La precisión de la clasificación obtenida fue testeada aplicando el método de la matriz de error. Como valor real de las clases se han empleado las imágenes de fotografía aérea. Se ha utilizado la orto imagen (fuente Google Maps, http:// maps.google.es) resultante para el establecimiento de las áreas de chequeo de la clasificación.

Posteriormente, se ha calculado la matriz de contingencia, obteniéndose un parámetro kappa de 0.72 . El margen de precisión de la clasificación ha resultado mayor del $79 \%$, y el porcentaje de píxeles no clasificados el $1 \%$, parámetros muy dependientes de las clases, del entrenamiento aplicado y de la resolución espacial de las imágenes.

Figura 3. Algoritmo K-Means aplicado a las imágenes TM 1987 (izqda.) y 2011 (dcha.)
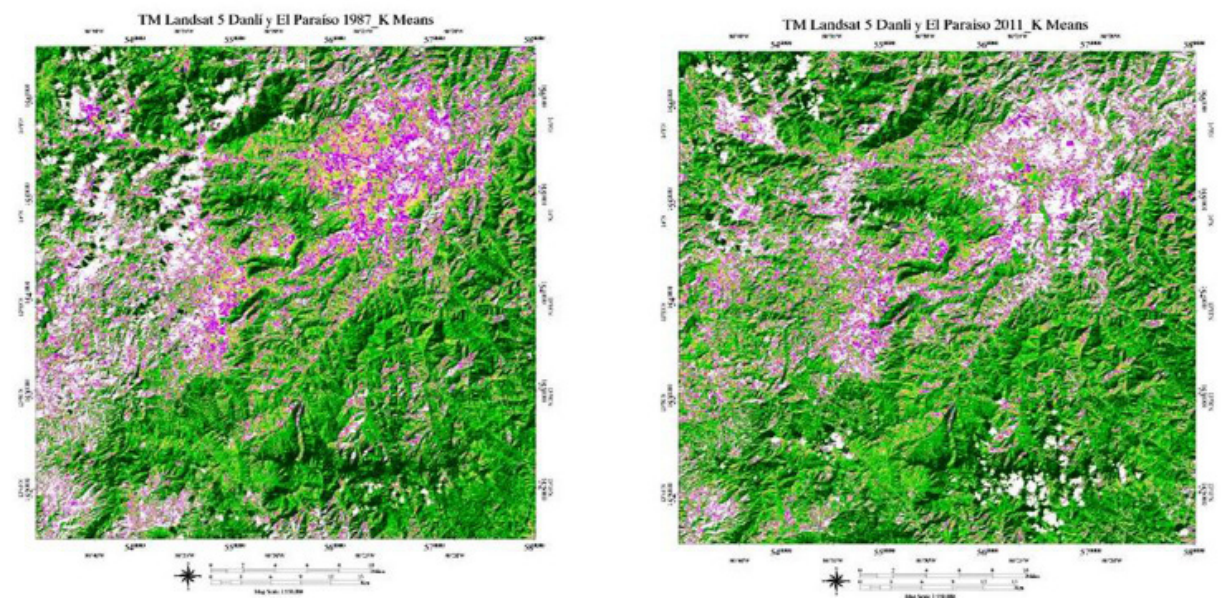

Los algoritmos aplicados K-Means e Isodata discriminan satisfactoriamente distintos tipos de cubierta entre sí como puedan ser monte alto, monte en la- 
dera, suelo desnudo, cultivos, vegetación en distintos estados fenológicos y en distintas ubicaciones (vegetación de ladera, vegetación de ribera, etc.), superficies artificiales típicas de entornos urbanos (hormigón, asfalto, cubiertas de edificios, tejas, etc.). Asimismo, se detecta aunque no se separan, dos clases informacionales más, sombras y nubes.

Las principales confusiones se han producido entre nubes y superficies de una reflectividad alta, como lo son las presentes en áreas urbanas, y entre sombras y distinto tipos de vegetación. También ha habido algún problema de confusión entre cubiertas con relleno de grava y caminos. Es decir, superficies de fondo que contienen materiales de composición coincidentes con los de las cubiertas muestran errores de confusión. Trabajos previos (Rejas et al., 2009) ponen de manifiesto la utilidad de líneas de contorno extraídas de las propia imagen para diferenciar espacios cerrados a nivel de suelo respecto de las cubiertas de edificios.

\section{DETECCIÓN DE CAMBIOS. VALIDACIÓN DE RESULTADOS}

Se ha realizado una validación de campo mediante el muestreo in situ de punto de test, que han sido georreferenciados y en los que se ha recogido información exhaustiva de las cubiertas presentes.

Para realizar la validación en las áreas de entrenamiento seleccionadas, se ha visitado la zona identificando el tipo de material en las cubiertas de interés. La clasificación basada únicamente en la imagen no requiere de un conocimiento previo de las diferentes tipos de superficie presentes, ni necesariamente de su firma espectral que se puede extraer de la imagen calibrada. Pero la validación y comprobación de la clases espectrales extraídas de los algoritmos K-Means e Isodata aplicados, sí que necesita de una supervisión e identificación de campo.

Se han registrado seis áreas de supervisión que eran accesibles, de las que se han tomado muestras para ser medidas con espectro radiómetro ASD Field-Pro

En la Tabla 1 se presentan fotografías con las coordenadas geográficas respectivas y descripción de las características de la cobertura del sitio para validar la clasificación digital realizada. Se hizo un recorrido por la zona, tomando los datos de las diferentes zonas de interés, tomando en cuenta la accesibilidad de los mismos. 
Tabla 1. Áreas de verificación

\begin{tabular}{|l|l|}
\hline \multicolumn{1}{|c|}{ Descripción y coordenadas } & Fotografía \\
\hline $\begin{array}{l}\text { Área de cultivo extensivo, pasto, } \\
\text { granos básicos según la estación } \\
\text { del año. El Benque, Jamastrán. } \\
\text { Coordenadas (UTM) } \\
16 \text { P 0561787 } \\
\quad 1550609\end{array}$ \\
$\begin{array}{l}\text { 1550 } \\
\text { 1553703 }\end{array}$
\end{tabular}




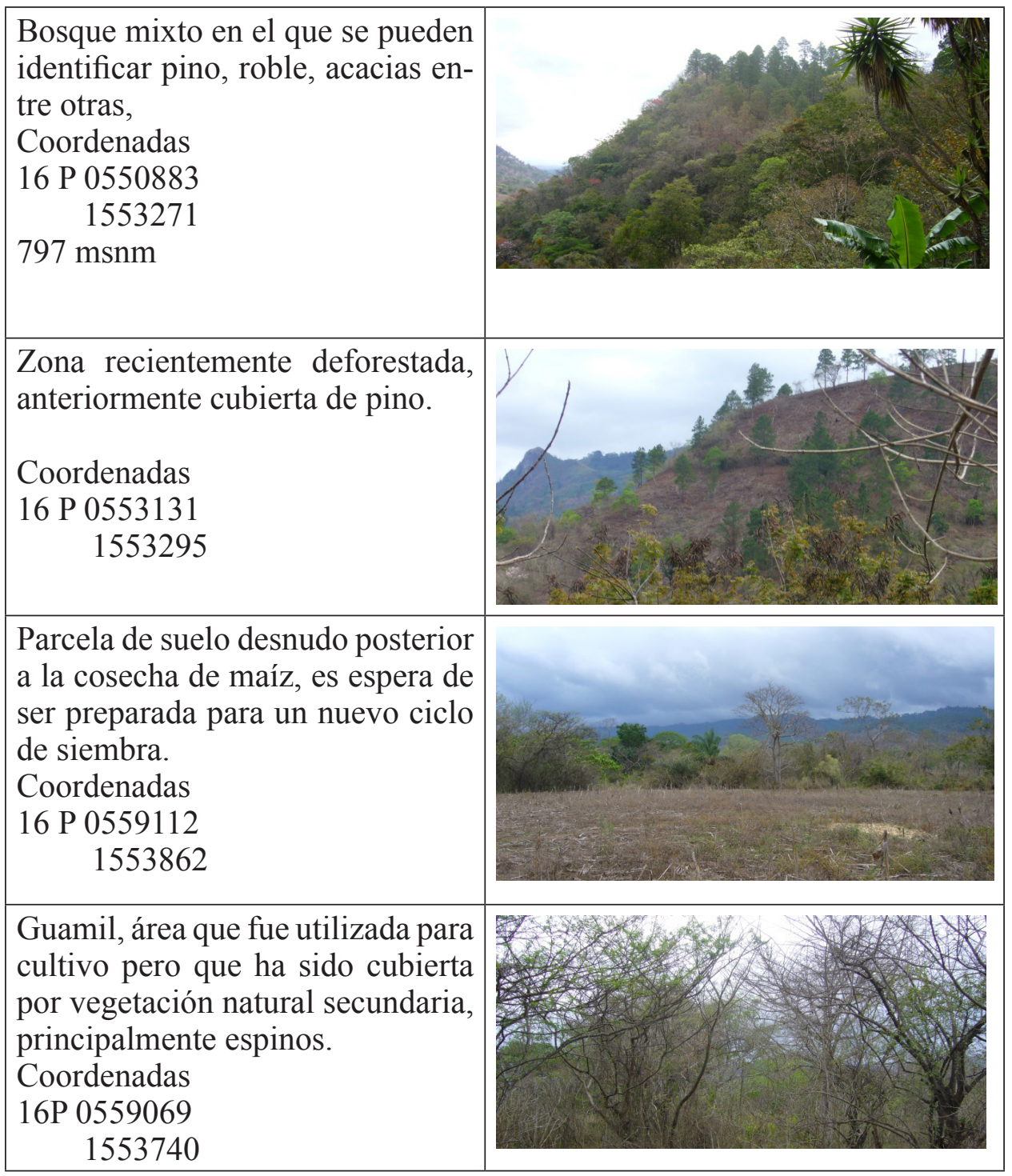

Asimismo, se realizó un análisis espectral de laboratorio con el objeto de determinar los rasgos espectrales característicos de cada una de las áreas de entrenamiento seleccionadas. Para ello se han empleado los espectros medidos in situ en las mismas condiciones de observación e iluminación de las imágenes, y espectros de superficies artificiales procedentes de librerías espectrales. Se ha calculado la tasa de cambio, obteniéndose un parámetro kappa de la matriz de 
confusión de 0.71 , valor admisible e indicativo de la elevada precisión alcanzada en el proceso.

Figura 4: Detección de cambios entre 1987 (izqda.) y 2011 (dcha.), con áreas en rojo (+5) y en azul (-5) que mayor dinámica de cambio han experimentado (centro). Detalle de la ciudad de Danlí y alrededores.
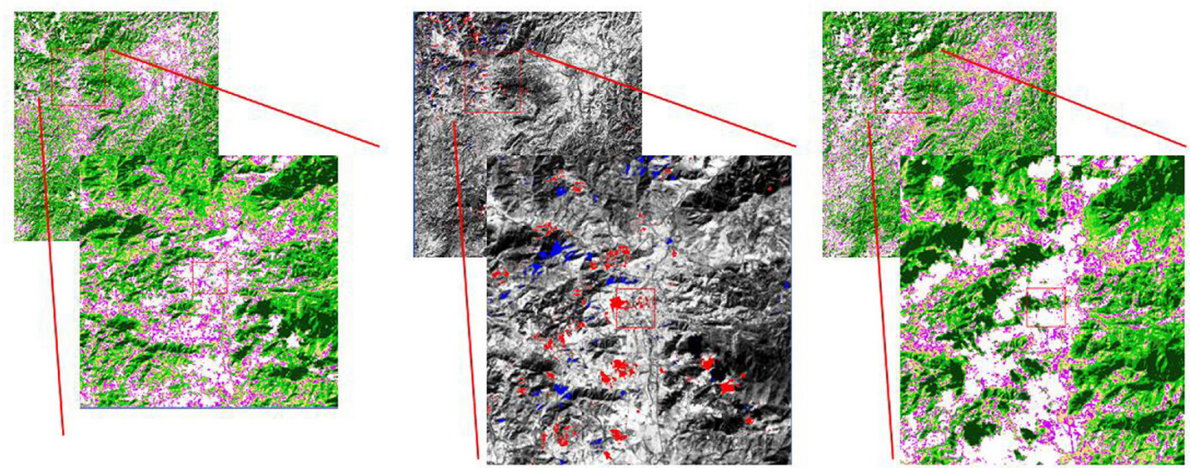

Tabla 2. Ejemplo de porcentajes de cambio en Danlí, ciudad y entorno, entre 1987 y 2011

\begin{tabular}{|c|c|c|c|c|c|c|c|}
\hline & Mont2 & Veget1 & Urbano & $\mathrm{Urb} / \mathrm{C} / \mathrm{N}$ & Mont1 V & Veget $2 / \mathrm{P}$ & Suelo lad \\
\hline Monte1/sombra & 22.381 & 5.677 & 0.716 & 1.991 & 54.605 & 2.117 & 1.174 \\
\hline Monte2/quebs & 37.807 & 19.899 & 0.860 & 1.997 & 14.464 & 5.044 & 1.432 \\
\hline Veget $1 /$ laderas & 19.865 & 35.886 & 3.450 & 3.340 & 7.770 & 23.230 & 9.059 \\
\hline $\begin{array}{l}\text { Veget } 2 / \text { pastos } \\
26.496\end{array}$ & 8.371 & 21.546 & 16.186 & 8.899 & 6.545 & 34.870 & \\
\hline $\begin{array}{l}\text { Suelo/laderas } \\
30.522\end{array}$ & 4.217 & 9.305 & 29.051 & 18.159 & 5.839 & 19.932 & \\
\hline $\begin{array}{l}\text { Urbano } \\
18.893\end{array}$ & 2.674 & 3.790 & 25.590 & 23.990 & 4.427 & 8.908 & \\
\hline $\begin{array}{l}\text { Urba/Cul/Nubs } \\
12.423\end{array}$ & 4.685 & 3.897 & 24.148 & 41.624 & 6.350 & 5.899 & \\
\hline Class Changes & 62.193 & 64.114 & 74.410 & 58.376 & 45.395 & 65.130 & 69.478 \\
\hline Image Differenc & 0.607 & 7.574 & 15.091 & -21.274 & -19.319 & 14.554 & \begin{tabular}{|l}
414.580 \\
4
\end{tabular} \\
\hline
\end{tabular}


Si bien se aprecia un cambio real entre determinadas clases informaciones (vegetación de ladera, urbano y cultivos, por ej.) en el período comprendido entre 1987, 1997 y 2011, se comprueba no obstante cómo los mayores porcentajes de cambio son debidos a causas coyunturales en las imágenes utilizadas, principalmente a la presencia de nubes y sombras, y también a los distintos estados fenológicos de cultivos y vegetación natural.

\section{CONCLUSIONES}

El área no presenta un cambio significativo en las diferentes coberturas, la variación en el uso es debido a la naturaleza agropecuaria de la zona, la estacionalidad de los diferentes cultivos y la dinámica normal de la población.

Es recomendable realizar monitoreos periódicos en las áreas de cultivo y establecer la dinámica de los mismos, realizar mapas de cultivo por estación del año, presencia de principales plagas agrícolas y zonas de incidencia para tomar medidas de prevención y saneamiento.

Verificar el crecimiento urbano y establecer si existen zonas de riesgo, establecer las mejores áreas para la expansión de núcleos urbanos, asegurando la sostenibilidad y sustentabilidad de los mismos.

\section{Agradecimientos}

Se agradece la colaboración brindada por la coordinación de la Maestría en Ordenamiento y Gestión del Territorio, la Universidad Nacional Autónoma de Honduras y la Universidad de Alcalá de Henares para la realización de este estudio.

\section{BIBLIOGRAFÍA}

- Ambrosio. Gonzales, J. y Arévalo, V., (2005). Detección de cambios urbanos mediante comparación de imágenes multitemporales. Málaga: Departamento de Ingeniería de Sistemas y automática. Universidad de Málaga.

- Antón-Pacheco, C., de Miguel E., Gumiel, J.C., Gómez, J.A., Gutiérrez, O., Rejas, J. G., Arranz, J., López, J.E., Barettino, D. y Jiménez, M., (1999). "Cartografía del vertido de lodos de la mina de Aznalcóllar mediante imágenes Daedalus ATM". Revista de teledetección de la Asociación Española de Teledetección (AET). Disponible en: http://age.ieg.csic.es/metodos/docs/doc3_1.pdf 
- Arango G.,M.,Branch, John y Botero V. (2005). "Clasificación no supervisada de coberturas vegetales sobre imágenes digitales de sensores remotos: Landsat-ETM+" Revista FNA, Medellín. Vol. 58, No. 1, pp. 2611-2634.

- Chuvieco, E. (2002). Teledetección ambiental. Madrid: Editorial Ariel.

- Di Gregorio A., Jansen L.J.M. (2000). "Land Cover Classification System (LCCS)". F.A.O.

- Latifovic R., Zhi-Liang Zhu, Cihlar J., Giri C., Olthof I. (2004). "Land cover mapping of North and Central America--Global Land Cover 2000" Remote Sensing of Environment, 89: 1, 116-127.

- Rejas J.G. Malpica J. A. y Martínez R. (2007). "Aplicación de teledetección hiperespectral en la identificación de cubiertas en áreas semi-urbanas". Congreso Internacional, $7^{\text {a }}$ Semana de Geomática, Barcelona (España) 20-23, febrero 2007.

- Salvatierra, H. y Pérez U. (1997). "Análisis multitemporal de la cobertura y uso de la tierra con apoyo de los sensores remotos" VIII Simposio Latinoamericano de Percepción Remota y Sistemas de Información Espacial. Mérida, Venezuela. Disponible en:http://desarrollo.ut.edu.co/tolima/hermesoft/portal/home_1/ rec/arc_6010.pdf

- Secretaría de Gobernación y Justicia de Honduras (s.f.). "Cuadro de intervenciones de ordenamiento territorial en el municipio" Unidad de registro de normativas de ordenamiento territorial RENOT. Disponible en: http://www.gobernacion.gob.hn/MapasDGOT/mapapot.html 